\title{
O EMPOBRECIMENTO CAUSADO PELA EROSĀO E PELA CULTURA ALGODOEIRA NO SOLO DO ARENITO BAURU()
}

F. Grohmann, engenheiro agrônomo, Seçãa de Conservação do Solo e R. A. Catani, engenheiro agrônomo, Seção de Agrogeologia, Instituto Agronômico de Campinas.

\section{1-INTRODUÇÃO}

Do ponto de vista agrícola, a região do Arenito Bauru, que cobre aproximadamente vinte e cinco por cento da área do Estado de São Paulo, é das mais importantes, pois oitenta por cento da produção algodoeira e mais de sessenta por cento da cultura de café estão localizados nesse tipo de solo. Aliado a essa intensidade de exploração agrícola, há o fato de ser êsse solo o mais erodível, dentre os que encontramos em nosso Estado. Por essas razóes, achamos oportuna a apresentação de alguns dados preliminares sôbre o empobrecimento dêsse solo, causado pela erosão e pela cultura algodoeira, bem como algumas orientações sôbre as adubaçōes aconselháveis.

Os dados que apresentamos foram colhidos na Estação Experimental do Instituto Agronômico, em Pindorama, situada na região do Arenito.

Os estudos referentes ao transporte dos elementos nutritivos em material erodido têm sido realizados principalmente nos Estados Unidos, onde é sabido que as pesquisas sôbre solos e sua conservação têm atingido nível muito superior ao dos demais países. Daí nos cingirmos sòmente à revisão da literatura norte-americana, sôbre o assunto.

Middleton, Slater e Byers (7), realizando pesquisas sôbre a erosão do solo, mostraram que, nos casos onde as perdas por erosão eram pequenas, o material erodido continha uma percentagem mais elevada de partículas minerais finas e de matéria orgânica do que o solo original. Pierre (13) acentua o fato de ser o fósforo encontrado, principalmente, nas partículas finas do solo e de serem elevadas as perdas por erosão, nesse elemento. Duley (3), Miller (8), Miller e Krusekoph (9), Neal (10), Scarseth e Chandler (14) mostram que as perdas de elementos nutritivos, pela erosão, são maiores que as quantidades removidas pelas culturas. Estes últimos autores indicam ainda que, em experiências de adubação com superfosfato, num período de 26 anos, 32 por cento do fosfato foram utilizados pelas plantas, 8 por cento foram retidos como resíduo, e 60 por cento foram perdidos pela erosão do solo.

Vê-se, pois, que é de grande importância avaliar as perdas de elementos fertilizantes no material erodido e procurar os meios de restitú-los ao solo.

(1) Trabalho apresentado na Segunda Reunião Brasileira de Cjência do Solo, realizada em Campinas, São Paulo, de 11 a 23 de julho de 1949. 


\section{2-ERODIBILIDADE DOS PRINCIPAIS TIPOS DE SOLO DO ESTADO DE SÃO PAULO}

Vários são os fatôres que afetam a erosão do solo. Se supusermos que todos permaneçam constantes, salvo o fator solo, verificaremos que alguns erodem mais, e que existe uma série de caraterísticas que tornam uns solos mais erodíveis que outros. Middleton e seus colaboradores (6, 7) realizaram estudos sôbre as propriedades físicas e químicas, que podem influenciar a erosão, e, como resultado de tais estudos, propuseram a "razão de erosão" para avaliar a erodibilidade dos solos.

Bouyoucus (1) apurou que o princípio fundamental, que condiciona a relativa erodibilidade dos solos, é a relação de "areia total mais limo" sôbre "argila total". Essa relação é chamada "razão de argila", e é o índice que mostra, satisfatòriamente, a erodibilidade. Aplicando a "razão de argila", para os principais tipos de solos do Estado de São Paulo (11), vamos encontrar os valores constantes do quadro 1.

Quadro 1.-Percentagem de areia grossa, limo mais areia fina, argila e "razão de argila", nos principais tipos de solos do Estado de São Paulo

\begin{tabular}{c|c|c|c|c}
\hline Tipo de solo & Areia grossa & Limo mais areia fina & Argila & Razäo de argila \\
\hline & $\%$ & $\%$ & $\%$ & \\
Arenito Bauru ...... & 75 & 15 & 10 & 9 \\
Arqueano ......... & 45 & 35 & 20 & 4 \\
Terra roxa ........ & 8 & 60 & 32 & 2 \\
\hline
\end{tabular}

Os valores altos para "razão de argila" indicam grande suscetibilidade do solo à erosão.

Comparando-se os resultados experimentais de perdas de solo e enxurrada, obtidos pela Seç̧ão de Conservação do Solo do Instituto Agronômico (4), por meio de sistemas coletores, com os valores da "razão de argila", mencionados no quadro 1, observa-se que o valor dessa "razão de argila" é correlacionado com a erodibilidade.

Verifica-se, pois, que o solo proveniente do Arenito Bauru é o mais erodível, donde a necessidade de se tomarem medidas urgentes de contrôle da erosão que aí se processa.

\section{3-PERDA DA FERTILIDADE DO SOLO DO ARENITO BAURU}

Para estudo da perda de material arrastado pela erosão, em solo procedente do Arenito Bauru, foram instaladas pela Secção de Conservação do Solo do Instituto Agronômico de Campinas, em 1943 (5), na Estação 
Experimental de Pindorama, localizada em solo típico dessa formação, várias séries de talhões experimentais munidos de sistemas coletores de material erodido.

Primeiramente, determinou-se a riqueza do solo original dêsses talhóes. A seguir, analisou-se o material erodido, a fim de se obter a sua riqueza média em elementos nutritivos. Medindo-se o total de material erodido em talhões experimentais cultivados com o algodoeiro, e levando-se em conta a sua riqueza, pôde-se avaliar a perda dos principais elementos nutritivos causados pela erosão em áreas cultivadas com essa planta. Calculando-se a quantidade de elementos nutritivos que uma cultura normal retira do solo, pôde-se fazer um confronto entre a quantidade de elementos retirados pela planta e a arrastada pela erosão do solo do Arenito Bauru.

\section{1-RIQUEZA DO SOLO ORIGINAL}

Dos talhões experimentais munidos de sistemas coletores de solo e enxurrada, foram retiradas amostras de solo até a profundidade de 40 centímetros, a fim de se determinar a riqueza média, antes de se iniciarem os estudos referentes às perdas por erosão. No quadro 2, apresentamos as médias das análises químicas realizadas nesse solo original.

QUADRo 2.-Riqueza média das amostras do solo original, solo transportado e da enxurrada, dos talhões experimentais instalados na Estação Experimental de Pindorama, em solo do Arenito Bauru

\begin{tabular}{|c|c|c|c|c|c|c|c|c|}
\hline \multirow{2}{*}{ Material analisado } & \multicolumn{6}{|c|}{ Teor trocárel } & \multirow{2}{*}{ Mat. Org. } & \multirow{2}{*}{$\mathbf{N}$} \\
\hline & $\mathbf{K}^{+}$ & $\mathrm{PO}_{4}$ & $\mathrm{Ca}^{++}$ & $\mathrm{K}_{2} \mathrm{O}$ & $\mathrm{P}_{2} \mathrm{O}_{5}$ & $\mathrm{CaO}$ & & \\
\hline & m.e. & m.e. & m.e. & $\%$ & $\%$ & $\%$ & & \\
\hline Solo original ( ${ }^{(1)}$ & 0,178 & 0,303 & 3,890 & 0,0084 & 0,007 & 0,108 & 1,00 & 0,069 \\
\hline \multirow[t]{2}{*}{ Solo transportado $\left({ }^{2}\right)$} & 0,410 & 0,870 & 7,660 & 0,019 & 0,020 & 0,213 & 2,10 & 0,125 \\
\hline & m.e./l & m.e./l & m.e. $/ l$ & $m g / l$ & $m g / l$ & $m g / l$ & & \\
\hline Enxurrada decantada () & 0,127 & 0,030 & 0,455 & 6,06 & 0,71 & 12,74 & & \\
\hline
\end{tabular}

(1) Médias de 12 amostras. (2) Médias de 19 amostras. (3) Médias de 11 amostras.

\section{2-RIQUEZA DO MATERIAL ERODIDO}

Dos coletores de material erodido, correspondentes aos talhoes experimentais, foram retiradas amostras, tanto de solo transportado, como da enxurrada, para análise química, cujos resultados também figuram no quadro 2. 
Comparando a riqueza em elementos nutritivos $\left(\mathrm{N}, \mathrm{P}_{2} \mathrm{O}_{5}, \mathrm{~K}_{2} \mathrm{O}, \mathrm{CaO}\right.$ e matéria orgânica) do solo original, expresso em percentagem, com o solo transportado pela erosão laminar, vê-se que o material erodido é 1,9 vêzes mais rico em nitrogênio, 2,8 vêzes em fósforo, 2,3 vêzes em potássio, 1,9 vêzes em cálcio e 2,0 vêzes mais rico em matéria orgânica, do que o solo original.

A maior riqueza do solo arrastado pela erosão poderá ser explicada em virtude da ação selecionadora da enxurrada, que transporta, primeiramente, e em maior proporção, as partículas mais finas, mais ativas do solo e, por conseguinte, mais ricas em elementos minerais. $\mathrm{Na}$ enxurrada, o elemento encontrado em maior proporção é o cálcio, com $12,7 \mathrm{mg}$ por litro. Segue-se o potássio, com $6 \mathrm{mg}$ por litro e, finalmente, o fósforo, com $0,7 \mathrm{mg}$ por litro.

Vemos que as perdas, por erosão, de elementos fertilizantes, no solo arenoso, são muito grandes, e devem ser consideradas como o fator de maior importância, do ponto de vista da perda de sua fertilidade.

\section{3-CONSUMO DE ELEMENTOS NUTRITIVOS PELA CULTURA} ALGODOEIRA

As culturas, por meio de suas colheitas, consomem grandes quantidades de elementos nutritivos. No Estado de São Paulo, uma das regióes mais intensamente cultivadas com o algodão, em virtude de sua fertilidade, aliada às condições topográficas favoráveis, é justamente onde ocorrem os solos arenosos do Arenito Bauru. Levando-se em consideração que o algodão é uma planta esgotante, por natureza, devemos estabelecer planos de reposição sistemática dos elementos consumidos pelas colheitas, se quisermos manter essa zona altamente produtiva.

As razões pelas quais somos obrigados a repor, no solo, os elementos minerais consumidos, se baseiam nas caraterísticas dêsse mesmo solo, ou seja, pobreza em minerais que contenham elementos químicos em estado potencial. Trata-se de solos férteis, quando novos, e que, com os métodos atuais de exploração, vão perdendo a fertilidade inicial ; uma vez empobrecidos, difìcilmente poderão ser restaurados.

Segundo dados preliminares, colhidos pela Secção de Conservação do Solo do Instituto Agronômico, na Estação Experimental de Pindorama (4), as perdas por erosão, em talhões com a cultura do algodoeiro, são aproximadamente de 37,3 toneladas de solo por hectare e 88 milímetros de altura de enxurrada por ano. Levando em consideração a riqueza média do material erodido constante do quadro 2, foi possível calcular o total de elementos nutritivos no solo transportado e na enxurrada nesses talhres cultivados com o algodão. Estes dados acham-se na primeira parte do quadro 3. 
QUADro 3.-Perdas de elementos minerais causadas pela erosão, segundo dados obtidos nos talhões experimentais da Estação Experimental de Pindorama, em solo do Arenito Bauru, comparadas com os elementos retirados do solo, de um modo geral, pela cultura do algodão

\begin{tabular}{|c|c|c|c|c|c|}
\hline $\begin{array}{l}\text { Agentes do empobrecimento } \\
\text { do solo }\end{array}$ & Nitrogênio & Fósforo & Potássio & Cálcio & $\begin{array}{l}\text { Matéria } \\
\text { Orgânica }\end{array}$ \\
\hline & $k g / h a$ & $k g / h a$ & $k g / h a$ & $k g / h a$ & $k g / h a$ \\
\hline $\begin{array}{l}\text { Solo transportado ..... } \\
\text { Enxurrada decantada. . }\end{array}$ & 46,5 & $\begin{array}{l}7,4 \\
0,6\end{array}$ & $\begin{array}{l}7,0 \\
5,3\end{array}$ & $\begin{array}{l}79,0 \\
11,2\end{array}$ & 780,0 \\
\hline Erosão total $\ldots \ldots \ldots \ldots \ldots$ & 46,5 & 8,0 & 12,3 & 90,2 & 780,0 \\
\hline Cultura do algodoeiro ( ${ }^{1}$ ) & 13,5 & 4,5 & 6,5 & 1,9 & \\
\hline Perdas totais & 60,0 & 12,5 & 18,8 & 92,1 & 780,0 \\
\hline
\end{tabular}

(1) Dados obtidos por Brown (2). Em Sáo Paulo foram obtidos, pela Seç̧ão de Agrogeologia do Instituto Agronômico (12), dados aproximados para os elementos : fósforo, potássio e cálcio.

Êstes dados evidenciam o enorme arrastamento de elementos nutritivos do solo, principalmente de matéria orgânica.

0 transporte dêsses elementos 6 favorecido, em virtude de coincidirem as chuvas mais intensas com a fase da cultura em que o solo se acha mais revolvido e menos protegido por cobertura vegetal. Chuvas excessivas ocorrem desde a semeadura até as colheitas, de tal modo que, em culturas como a de algodão, que oferecem pequena proteção ao solo, os seus elementos nutritivos e os que nêle forem incorporados são fàcilmente transportados.

$O$ algodoeiro, segundo Brown (2), com uma produção de 100 arrôbas por alqueire $(620 \mathrm{~kg} / \mathrm{ha})$ de algodão em caroço, retira do solo, em quilos por hectare, as seguintes quantidades de elementos : nitrogênio $=13,5$; fósforo $=4,5 ;$ potássio $=6,5$ e cálcio $=1,9$. Dados obtidos no Instituto Agronômico, pela Seç̧ão de Agrogeologia (12), em solos do Estado de São Paulo, mostram que, para uma produção idêntica, o algodoeiro retira, considerando apenas as sementes, as seguintes quantidades de elementos, em quilos por hectare : fósforo $=5,0$; potássio $=4,2$ e cálcio $=1,3$. Por êstes dados, verifica-se que o consumo de elementos nutritivos, pelo algodoeiro, foi, em nossas condições, comparável ao obtido por Brown, quadro 3 , com exceção do nitrogênio, que não foi analisado.

Os dados da última linha do quadro 3 correspondem ao total de elementos nutritivos retirados em um hectare de solo, pela erosão e pela cultura algodoeira.

Confrontando-se a quantidade de elementos arrastados pela erosão com a que o algodão retira do solo, verifica-se que aquela é muito maior. Daí a grande necessidade da intensificação das práticas de conservação no solo arenoso. 


\section{4-ADUBAÇÃO DO SOLO DO ARENITO BAURU}

Conforme esclarecem os dados apresentados, o empobrecimento anual do solo do Arenito Bauru, pela erosão, é elevado e maior que o determinado pela cultura algodoeira.

Este fato é de muita importância, e suas consequências incidem diretamente no problema da adubação em geral. Em virtude do seu baixo teor em argila e em matéria orgânica, apresenta êsse tipo de solo uma capacidade de adsorção (retenção) dos elementos fertilizantes muito baixa e, como resultado, não só o fenômeno de transporte de material sólido é relativamente grande, como também é elevado o de simples lavagem das substâncias de interêsse à nutrição vegetal.

Considerando-se que a queda pluviométrica se processa, na maior parte, no período de outubro-março, o uso de fertilizantes nessa região deverá ser muito bem conduzido, a fim de evitar perdas pelos fenômenos citados.

Em primeiro lugar, julgamos que a adubação deveria ser indicada nesse solo, preferìvelmente, em áreas já submetidas a práticas conservavacionistas, para reduzir ao mínimo as perdas de fertilizantes.

A adubação básica deveria ser orgânica, para aumentar o teor em colóides, que é muito baixo, pois o teor em argila no solo do Arenito Bauru não vai além de 10 por cento. Adubação orgânica, nas suas variadas formas, além dos benefícios que causa, modifica a textura do solo, determinando um acréscimo na sua capacidade de adsorção e, como consequência, assegurando a retenção dos elementos fertilizantes em maior escala.

Dentre os fertilizantes nitrogenados, as formas orgânicas (tortas, farinhas de sangue, etc.) deveriam ser preferidas, sempre que as particularidades das culturas não as contra-indicarem (ciclo muito curto, culturas de inverno, etc.). Quando forem aconselháveis os fertilizantes nitrogenados minerais, especialmente o nitrato de sódio e sulfato de amônio, sua incorporação ao solo, em parcelas, deveria ser a regra, para que as culturas tivessem maior possibilidade de absorvê-los.

Em relação aos fosfatos, a associação da forma solúvel em água à solúvel em ácido cítrico a 2 por cento, variando as proporçóes conforme caraterísticas da cultura, parece satisfazer a maioria dos casos, porque os fosfatos são, dentre os fertilizantes, os mais retidos no solo.

A adubação potássica não oferece muita dificuldade quanto à escolha, porque as formas mais comuns são cloretos, sulfatos e carbonatos (cinzas vegetais), tôdas solúveis em água, apresentando-se o problema do mesmo modo que os nitrogenados minerais.

Em resumo, a solução da adubação no solo procedente do Arenito Bauru deverá sempre procurar atender as caraterísticas de textura dêste tipo de solo e sua capacidade de adsorção dos elementos fertilizantes. 


\section{5-RESUMO E CONCLUSÕES}

O empobrecimento do solo causado pela erosão e pela cultura algodoeira foi estudado em talhões experimentais, munidos de sistemas coletores, que a Secção de Conservação do Solo tem instalados na Estação Experimental do Instituto Agronômico de Campinas, em Pindorama, região representativa do solo tipo Arenito Bauru. E nesse solo que atualmente se encontram sessenta por cento da área cultivada com café e oitenta por cento da área com o algodão, no Estado de São Paulo.

Os dados colhidos, embora preliminares, são considerados de grande interêsse, e indicam que o empobrecimento dêsse solo é bastante rápido pelo efeito da erosão, pois é o de maior erodibilidade em São Paulo.

Foram realizadas análises químicas do solo original dos talhões experimentais, do solo transportado e das enxurradas, a fim de se avaliar a sua riqueza média. Verificou-se que o solo transportado pela erosão é bem mais rico em elementos minerais do que o solo original. $O$ solo transportado possui 2,0 vêzes mais matéria orgânica ; 2,8 mais $\mathrm{P}_{2} \mathrm{O}_{5} ; 2,3$ mais $\mathrm{K}_{2} \mathrm{O}$ e 1,9 vêzes mais $\mathrm{CaO}$ do que o solo original. Na enxurrada, o elemento encontrado em maior proporção foi o cálcio.

Baseando-se na quantidade total de perdas por erosão em talhões cultivados com algodão, calculou-se o total de elementos nutritivos transportados nesse solo e na enxurrada. Avaliou-se também a quantidade de elementos minerais retirados do solo pela cultura do algodoeiro, fazendo-se, a seguir, um confronto entre êsses dados e os relativos à perda pela erosão. Verificou-se que o empobrecimento do solo é muito mais acentuado pela erosão do que apenas pela cultura do algodoeiro.

Levando-se em consideração a natureza física e química do solo do Arenito Bauru, foram feitas algumas considerações sôbre formas de adubação orgânica e minerais a serem empregadas.

\section{SUMMARY}

The empovrishment of the soil brought about by erosion and cultivation of cotton has been studied in experimental plots where catch tanks were employed to collect soil removed by erosion. These tests have been carried out by the Soil Conservation Department at the Experiment Station of the Instituto Agronômico of Campinas, in Pindorama, and on the "Arenito Bauru" soil type representative of the region. Actually sixty percent of all coffee and eighty percent of all cotton cultivation in the State of São Paulo is on the "Arenito Bauru" soil type. Thus the data collected, although preliminary, are of great interest, and indicate that the empovrishment of the "Arenito Bauru" soil by erosion is extremely rapid. It is also pointed out that the "Arenito Bauru" soils are the most highly erodable of all soil types in the State of São Paulo.

A chemical analysis was made of representative samples of the original soils in the experimental plots and of samples of soil carried in the runoff, for the purpose of determining the losses due to erosion. It has been determined that the soil transported in the runoff is proportionally very much richer in mineral elements than was the original soil. The data obtained from analysis of samples showed that soil eroded from the experimental plots contained 2.0 times as much organic material, 2.8 times as much $\mathrm{P}_{\varepsilon} \mathrm{O}_{5}$; 2.3 times as much $\mathrm{K}_{2} \mathrm{O}$, and 1.9 times as much $\mathrm{CaO}$, as was determined present in the samples obtained from the original soil of the experimental plots. In the runoff water it has determined that calcium was present in larger quantities than other elements. 
On the basis of data obtained from the experimental plots with cotton cultivation, an evaluation and comparison was made of the amount of mineral elements lost by erosion and the amount used by the cotton crop. It was found that the empovrishment of the soil by loss of organic material and chemical elements was due more to erosion than to utilization of these in the production of harvested cotton.

A discussion is given of forms of organic and mineral fertilizers to be employed on "Arenito Bauru" soils, taking into consideration the physical and chemical nature of these soils.

\section{LITERATURA CITADA}

1. Bouyoucus, G. J. The clay ratio as a criterion of susceptibility of soils to erosion. Jour. Amer. Soc. Agron. 27 : 738-741. 1935.

2. Brown, H. B. Em Cotton, pág. 216-227, 2." ed. McGraw-Hill Book Co. 1938.

3. Duley, F. L. The loss of soluble salts in runoff water. Soil. Sci. 21 : 401-409. 1926.

4. Marques, J. Q. A., F. Grohmann, J. Bertoni e F. M. A. de Alencar. Relatório da Secção de Conservação do Solo. Divisão de Experimentação e Pesquisas. (Instituto Agronômico). 1947/48. (Não publicado).

5. Marques, J. Q. A. Relatórios da Secção de Conservação do Solo. Divisão de Experimentação e Pesquisas (Instituto Agronômico). 1943, 1944 e 1945. (Não publicados).

6. Middleton, H. E. The properties of soils which influence erosion. Tech. Bul. of U.S. D.A. 178.1930.

7. Middleton, H. E., C. S. Slater and H. G. Byers. The physical and chemical characteristics of soils from the erosion experiment station. Tech. Bul. of U.S. D. A. 430 : $18-58.1934$.

8. Miller, M. F. Waste through soil erosion. Jour. Amer. Soc. Agron. 18 : 153-160. 1926.

9. Miller, M. F. and H. H. Krusekoph. The influence of systems of cropping and methods of culture on surface runoff and soil erosion. Res. Bul. of Mo. Agr. Exp. Sta. $177: 24-25.1932$.

10. Neal, O. R. The influence of soil erosion on fertility losses and on potato yeild. Amer. Potato. Jour. 20 : 57-64. 1934.

11. Paiva Neto, J. E. A "fração argila" dos solos do Estado de São Paulo e seu estudo roentgenografico. Bragantia 2: 355-432. 1935.

12. Paiva Neto, J. E., R. A. Catani e A. Küpper. A composição mineral de algumas plantas cultivadas no Estado de São Paulo. Trabalho apresentado à Segunda Reunião Brasileira de Ciência do Solo. Campinas, São Paulo, julho de 1949. (Não publicado).

13. Pierre, W. H. Phosphorus deficience and soil fertility. Em Yearbook of U. S. D. A. 1938 : $377-396.1938$.

14. Searseth, George D. and W. V. Chandler. Losses of phosporus from a light testured soil in Alabama and its relation to some aspects of Soil Conservation. Jour. Amer. Soc. Agron. 30 : 361-374. 1938. 